\title{
Chlamydia trachomatis infection and maternal outcomes in Southern Ghana
}

\author{
Mate Siakwa ${ }^{1}$, Dzigbodi Kpikpitse ${ }^{2}$, Wisdom Azanu ${ }^{3}$, Robert Bella Kuganab-Lem ${ }^{4}$, \\ Emmanuel Hanson-Owoo ${ }^{5}$
}

\author{
${ }^{1}$ School of Nursing, University of Cape Coast, Ghana \\ ${ }^{2}$ School of Nursing, Garden City University College Kumasi, Ghana \\ ${ }^{3}$ Department of Obstetrics and Gynaecology, Komfo Anokye Teaching Hospital, Kumasi, Ghana \\ ${ }^{4}$ School of Allied Health, University for Development Studies Tamale, Ghana \\ ${ }^{5}$ Cape Coast Teaching Hospital Cape Coast Ghana
}

Received: 29 January 2016

Revised: 03 March 2016

Accepted: 08 March 2016

\section{*Correspondence:}

Mate Siakwa,

E-mail: msiakwa@yahoo.co.uk

Copyright: ( $)$ the author(s), publisher and licensee Medip Academy. This is an open-access article distributed under the terms of the Creative Commons Attribution Non-Commercial License, which permits unrestricted non-commercial use, distribution, and reproduction in any medium, provided the original work is properly cited.

\begin{abstract}
Background: Despite the fact that Chlamydia trachomatis (CT) infection in pregnancy is known to have grave impact on maternal and neonatal health, routine CT screening in pregnancy is not available in Ghana The main aim of this study was to determine the prevalence and adverse maternal outcomes of CT infection among pregnant women attending antennal clinic at the Cape Coast Teaching Hospital.

Methods: Two hundred and thirty two (232) pregnant women screened for CT infection by PCR were purposively selected and enrolled into the study after informed consent had been obtained. They included one hundred and twelve (112) participants with positive CT (cases) and 120 participants without CT infections (control). A structured questionnaire was used to collect their socio demographic, obstetric and medical history. They were monitored thereafter and data on maternal outcomes were collected.

Results: The prevalence of CT infection was 5.6\% (112/2014). A history of STI/UTI $(p<0.001)$ spontaneous abortion $(\mathrm{p}=0.02)$, preterm labour $(\mathrm{p}<0.001)$ and intrapartum or postpartum fever $(\mathrm{p}<0.001)$ were found to be associated with $\mathrm{CT}$ infection. However a history of Stillbirth, PID and having been treated for infertility were not associated with CT infection. Participants with CT infection were more likely to have PROM $(p<0.001)$ and FSL $(p<0.001)$ than those who were not infected. Parity and mode of delivery on the other hand were not associated with CT infection. Conclusions: To alleviate the adverse maternal outcomes, screening for CT infection in pregnancy should be offered routinely to pregnant women to promote early detection and treatment.
\end{abstract}

Keywords: Chlamydia, infection, obstetric outcomes, Ghana

\section{INTRODUCTION}

Chlamydia trachomatis (CT) is a major cause of genitourinary infections with serious implication for maternal and neonatal health. ${ }^{1}$ Majority of the CT infections in women are usually asymptomatic hence many infected individual may go undetected. The prevalence of the infection could be as high as $7.7 \%$ in women receiving antenatal care to $19 \%$ among pregnant adolescents. $^{2,3}$ CT infection in pregnancy is associated with ectopic pregnancy, spontaneous abortion, preterm labour, amniotitis, and premature rapture of membranes. ${ }^{4-}$

10 Development of intra-partum fever and late onset endometritis after vaginal delivery has also been reported. Being a main cause of pelvic inflammatory disease CT is implicated in infertility. ${ }^{11-14}$

The impact of CT in pregnancy on neonatal and infant health has also been widely investigated. Some of the adverse outcomes are low birth weight, prematurity, still 
birth, and neonatal death. ${ }^{6-9}$ Vertical transmission of CT has been associated with conjunctivitis and pneumonia, otitis media, bronchitis, pharyngitis, rhinitis, and gastroenteritis. ${ }^{15}$

Screening for CT in pregnancy is considered the best intervention for detection and treatment to reduce the associated morbidities. ${ }^{16}$ Such screening programmes have reported increasing incidence of CT in the last two decades the world over. ${ }^{17}$ In spite of the devastating effects of CT infection during pregnancy, routine screening for CT infection is not available in resource poor countries. The main aim of the study is to determine the prevalence of CT infection among pregnant women and its implications for maternal outcome.

\section{METHODS}

\section{Design}

Descriptive case-control prospective study was conducted during the period of July 2006 and December 2012.

\section{Sampling}

A total of 2014 pregnant women attending antenatal clinics of the Cape Coast Teaching Hospital, Ghana during the study period were screened for CT. Two hundred thirty two (232) were purposively selected and enrolled in the study after informed consent had been obtained. These comprised one hundred and twelve (112) pregnant women with positive CT (cases) and 120 healthy pregnant women (control) who were negative for CT matched for gestational age. Women with known underlining pathology or chronic diseases that have adverse birth outcomes were excluded from the study.

\section{Personal data}

Pre-tested questionnaires with a Cronbach's alpha coefficient of 0.93 were used to obtain information on relevant medical, obstetrical and socio-demographic characteristics. History of spontaneous abortion, preterm labour (PTL), sexually transmitted infection, pelvic inflammatory disease (PID), intrapartum fever (IPF), and stillbirth.

\section{Physical examination}

Presence of cervicitis on physical examination was noted. The presence of cervical congestion, erythema, edema, and fragility in addition to copious mucopurulent discharge from the endocervical canal was defined as cervicitis

\section{Detection of CT by PCR}

Endocervical swabs were collected from all participants under sterile conditions and PCR technique was applied as described by Schmidt et al (2015)

\section{Obstetric outcome}

Participants were evaluated for presence of premature rupture of membranes (PROM) and premature labour, foul smelling liquor (FSL), Meconium stained amniotic fluid (MSAF), bleeding (ante-partum and post-partum) and mode of delivery.

\section{Ethical consideration}

The Institutional Review Board of the University of Cape Coast approved the study and ethical clearance was obtained from the hospital. Participants' also signed informed consent and participation was voluntary.

\section{Data analysis}

Data was analysed with SPSS 21. For the univariate analysis of categorical variables, Pearson's Chi square or Fisher's exact test was used. For continuous variables, we used the Independent sample t-test after checking normality and equality of the variance on the basis of Levine's test at $5 \%$ significance.

\section{RESULTS}

Two thousand and fourteen pregnant women were screened for CT during the study period of which 112 were positive. The prevalence of CT among the study population was $5.6 \%(112 / 2014)$. The mean age of the respondents was $24 \pm 4.6$ years. Forty eight $(43 \%)$ of those who tested positive were symptomatic.

Table 1 shows the socio-demographic characteristics of respondents. The age of the participants was found to be associated with CT infection. Those aged 20 -29 years were more likely to be infected. The majority of the women infected were of the low-income group. Ninety seven percent of CT infected individuals have had at least nine years of formal education. There was no significant difference in CT infections between urban and rural dwellers.

Table 2 shows the obstetric history of the participants. A history of STI/UTI $(p<0.001)$ spontaneous abortion $(p=0.02)$, preterm labour $(p<0.001)$ and intrapartum fever $(\mathrm{p}<0.001)$ were found to be associated with CT infection. However a history of Stillbirth, PID and having been treated for infertility were not associated with CT infection.

Table 3 shows the obstetric outcome of participants. Pregnant women with CT infection were more likely to have PROM $(p<0.001)$ and FSL $(p<0.001)$ than those who were not infected. Parity and mode of delivery on the other hand were not associated with CT infection. 
Table 1: Socio-demographic characteristics of respondents.

\begin{tabular}{|c|c|c|c|c|c|}
\hline Parameters & Variables & Case $(n=112)$ & Control $(n=120)$ & $X^{2}$ & p-value \\
\hline \multirow{4}{*}{ Age } & $<20$ & 6 & 8 & 14.1742 & 0.00017 \\
\hline & $20-29$ & 89 & 92 & & \\
\hline & $30-39$ & 8 & 11 & & \\
\hline & $\geq 40$ & 9 & 9 & & \\
\hline \multirow{3}{*}{ Income } & Low & 92 & 102 & 1.2633 & 0.5317 \\
\hline & Medium & 12 & 8 & & \\
\hline & High & 8 & 10 & & \\
\hline \multirow{4}{*}{$\begin{array}{l}\text { Educational } \\
\text { Level }\end{array}$} & Illiterate & 3 & 5 & 18.18477 & 0.00403 \\
\hline & Primary & 64 & 40 & & \\
\hline & Secondary & 39 & 51 & & \\
\hline & Tertiary & 6 & 24 & & \\
\hline \multirow{2}{*}{ Residence } & Rural & 52 & 58 & 0.0252 & 0.8738 \\
\hline & Urban & 60 & 62 & & \\
\hline
\end{tabular}

Table 2: Obstetric history of respondents.

\begin{tabular}{|c|c|c|c|c|c|}
\hline $\begin{array}{l}\text { Parameters/ } \\
\text { History of } \\
\text { respondents }\end{array}$ & Variables & Case $(n=112)$ & $\begin{array}{l}\text { Control } \\
(n=120)\end{array}$ & Chi Square & P-Values \\
\hline & Absent & 85 & 115 & & \\
\hline \multirow{2}{*}{$\begin{array}{l}\text { Spontaneous } \\
\text { abortion }\end{array}$} & Present & 18 & 7 & 5.2957 & 0.02138 \\
\hline & Absent & 94 & 113 & & \\
\hline \multirow[t]{2}{*}{ PID } & Present & 9 & 3 & 2.5787 & 0.1083 \\
\hline & Absent & 103 & 117 & & \\
\hline \multirow{2}{*}{ Preterm labour } & Present & 24 & 6 & 12.4664 & 0.0004 \\
\hline & Absent & 88 & 114 & & \\
\hline \multirow{2}{*}{ Intrapartum fever } & Present & 34 & 12 & 14.9804 & 0.00016 \\
\hline & Absent & 74 & 108 & & \\
\hline \multirow{2}{*}{ Stillbirth } & Present & 11 & 7 & 0.7905 & 0.3739 \\
\hline & Absent & 101 & 113 & & \\
\hline \multirow{2}{*}{ Treated infertility } & Present & 10 & 4 & 2.2878 & 0.1304 \\
\hline & Absent & 102 & 116 & & \\
\hline
\end{tabular}

Table 3: Maternal obstetric characteristics of respondents.

\begin{tabular}{|c|c|c|c|c|c|}
\hline Parameters & Variables & Case $(n=112)$ & Control $(n=120)$ & $\mathrm{X}^{2}$ & P-Values \\
\hline & 1 & 23 & 46 & & \\
\hline & 2 & 82 & 65 & & \\
\hline & $\geq 3$ & 7 & 9 & & \\
\hline \multirow{2}{*}{ PROM } & Present & 34 & 6 & 24.3583 & 0.0000 \\
\hline & Absent & 78 & 114 & & \\
\hline \multirow{2}{*}{ MSAF } & Present & 13 & 5 & 3.5019 & 0.0613 \\
\hline & Absent & 99 & 115 & & \\
\hline \multirow{2}{*}{ Foul smelling liquor } & Present & 24 & 5 & 14.1772 & 0.00017 \\
\hline & Absent & 88 & 115 & & \\
\hline \multirow{2}{*}{ Mode of delivery } & SVD & 100 & 107 & 0.0334 & 0.8500 \\
\hline & $\mathrm{CS}$ & $\mathrm{I} 2$ & 13 & & \\
\hline
\end{tabular}




\section{DISCUSSION}

This descriptive case-control study is the first to investigate the prevalence and consequences of CT infection among pregnant women in Ghana. A total of two thousand and fourteen pregnant women were screened for CT during the study period. The study uniquely identified adverse effects of CT during pregnancy on obstetric outcomes. PROM, FSL and a history of spontaneous abortion, preterm labour and intrapartum fever are important findings that are discussed. A prevalence rate of $5.6 \%$ was determined, and $43 \%$ of cases were symptomatic, consistent with what have been previously reported.,17

The majority (79\%) of the participants were between 20 and 29 years of age. This finding is consistent with what was reported earlier. ${ }^{12,18,19}$ The most predicting socio demographic factors with $\mathrm{CT}$ infection are age and educational level but not their place of residence and income.

CT infection was found to be associated with a history of STI or UTI. CT is known to be a major cause of urethritis. Several studies have reported co infections of CT with other STIs individuals with CT infections could contract other STI due to exposure from multiple sexual partners or reinfection from an untreated partner. ${ }^{16,20-22}$

The role of CT in spontaneous abortion has been widely investigated. Findings from these studies have not been consistent. The finding of the present study revealed statistically significant difference in spontaneous abortion between pregnant women infected with $\mathrm{CT}$ and those not infected. This finding is consistent with what has been reported elsewhere, while other studies reported lack of association between CT infection and spontaneous abortion. ${ }^{4,5,15,23-26}$ Several models have been proposed for the pathogenesis of chlamydia related spontaneous abortion. These include direct infection of the zygote, immune response to heat shock proteins expressed by the zygote that is triggered by reactivation of latent chlamydia infection and endometrial damage from chlamydia infection. The preferred pathway could be unique to individuals and may account for the variations. $^{4,30,33}$

Preterm delivery is the leading cause of perinatal morbidity and mortality, which warrants a continued and broadened research focus. ${ }^{27}$ The risks associated with Preterm birth are heterogeneous and genitourinary infection is one potential cause of preventable and amenable to treatment. ${ }^{26}$ The findings of this study indicated that CT infection is associated with preterm labour. This is consistent with the findings of numerous studies, however, others found no such association. ${ }^{6-9,28-30}$ Other studies have explain that the increased incidence of preterm labour and delivery associated with urogenital infections can result from inflammatory responses induced by cytokines and prostaglandins mediators triggered by the colonization of the amniotic fluid by uropathogens. These bacteria produce collagenase and phospholipases $\mathrm{A}$ and $\mathrm{C}$ which act as precursors of procontractile prostaglandins E2 and F2a, consequently triggering preterm labour. ${ }^{31,32}$ It has been reported that intrauterine infections are responsible for up to $50 \%$ of extreme preterm birth of less than 28 weeks of gestation where both neonatal morbidity and mortality are high. ${ }^{31}$ These intrauterine infections may have resulted from inflammation of the amniotic membrane and transplacental transfer of cytokines originating from maternal infection. ${ }^{33,34}$

The association between PROM and CT infection has been extensively investigated. Findings from these studies have been conflicting. The findings of the present study revealed that $\mathrm{CT}$ infection increased the risk of PROM, consistent with Baud et al on the contrary Silveria et al and Yalti et al reported no association of PROM with CT infection. ${ }^{10,29,30}$ A possible mechanism has been proposed to explain how infection in pregnancy caused the risk of PROM. According to Simmons et al and Bhuta et al urogenital infections induce macrophages to release metalloproteinase which degrades amniotic membranes predisposing them to rapture. ${ }^{31,34}$

Several studies have reported a significantly higher stillbirth in pregnant women infected with CT than those not infected, this study found no such association though the number of still births were higher in the infected group, consistent with the finding of $\mathrm{Li}$ et al. , $^{40,25,35,36}$

The presence of meconium in amniotic fluid is a predictor of neonatal infection. ${ }^{37}$ Normally it is expected that the amniotic fluid would remain clear. However in times of foetal hypoxia it could be stained with meconium. Lack of vertical transmission of CT in the infected individuals was evident in this study.

CT infection was found to be significantly linked to infertility. ${ }^{11-14}$ This study considered a history of treatment for infertility and identified a lack of association between a history of treatment for infertility and CT.

A history of intrapartum/post partum fever was significantly associated with CT infection. This was reported by previous studies. ${ }^{1,38} \mathrm{CT}$ infection during pregnancy may continue after delivery causing endometritis, salpingitis or PID, which may present as post-partum fever.

Several studies revealed an association of CT with PID. ${ }^{2,3,17,39,40}$ Notwithstanding, this study found no such significant association. The lack of association in this study could be attributed to the study design. This study did not screen the pregnant women for PID. Participants reported a history of PID and could not be an accurate way of assessing individuals for PID. 


\section{CONCLUSION}

The study revealed a high prevalence CT infection among pregnant women in the study area with most of those infected being asymptomatic. CT infection during pregnancy increased the risk of adverse maternal outcomes. The finding underscored the importance of routine CT screening of pregnant women for early detection and treatment to forestall these risks and reduce perinatal morbidity and mortality.

Funding: Not required

Conflict of interest: None declared

Ethical approval: The study was approved by the Institutional Ethics Committee

\section{REFERENCES}

1. Tiller CM. Chlamydia trachomatis during pregnancy implications and impact on perinatal and neonatal outcomes. J Obstet Gynecol. 2002;31:93-8.

2. Rekart M L, Brunham RC. Stable Chlamydia prevalence does not exclude increasing burden of the disease Sex Trasm Dis. 2012;39:239.

3. Scholes D, Satterwhite CL, Onchee Y, Fine D, Weinstock D, Berman S. Long term trends in Chlamydia trachomatis infections and related outcomes in a US managed care population. Sex Transm Dis. 2012;39:81-8.

4. Kishore J, Agarwal J, Agarwal S, Ayyagari A. Seroanalysis of Chlamydia trachomatis and $\mathrm{S}$ TORCH agents in women with recurrent spontaneous abortion in India J Pathol Microbiol. 2003;46:684-7.

5. Wilkowska-Trojniel M, Zdrodowska-Stefanow B. The influence of Chlamydia trachomatis on spontaneous abortion. Adv Med Sci. 2009;54:86-90.

6. Goldenberg R, Culhane J, Iams J, Romero R. Epidemiology and causes of preterm birth. Lancet. 2008;371:75-83.

7. Mathews $\mathrm{T} \mathbf{J}$ and MacDorman MF. Infant mortality statistics from 2006 period linked birth/infant death data set. Vital Stat Rep. 2010;58:1-31.

8. Rours GI, Duijts L, Moll HA, Arends LR, de Groot $\mathrm{R}$, Jaddoe VW et al. Chlamydia trachomatis infections during pregnancy associated with preterm delivery a population base based prospective cohort study. Eur. J Epidemiol. 2011;26(6):493-502.

9. Schmidt R, Muniz RR, Cola E, Stauffert D, Silvera MF, Marianda AE. Maternal Chlamydia trachomatis infections and preterm births in a University Hospital in Victoria, Brazil. 2015;PLoS ONE10(10):e0141367.

10. Baud D, Goy G, Jalton K, Osterheld MC, Blumer S, Borel $\mathrm{N}$ et al. Chlamydia trachomatis in miscarriage. Emmerg. Infect. Dis. 2011;17(9):1630-5.

11. Cates W, Wasserheit JN. Genital Chlamydia infections epidemiology and reproductive sequelae. Am J Obstet Gynecol. 1991;164(6):1771-8.
12. Flemming DT, Wasserheit JN. From Epidemiological synergy to public health policy and practice the contribution of other sexually transmitted diseases to sexual transmission of HIV infection. Sex Transm. Infect.1999; 75: 3-17.

13. Malik A, Jain S, Hakim S, Shukla I, Rizvi M. Chlamydia trachomatis infection and infertility. Indian J Med. Res. 2006; 123(6): 770-5

14. Siemer J, Theile O, Larbi Y, Fasching PA, Danso KA, Kreienberg $\mathrm{R}$ et al Chlamydia trachomatis infection as a risk for infertility among women in Ghana, West Africa. Am J Trop Med. 2008; 78(2):323-327

15. Sozio J, Ness RB. Chlamydia lower genital infection and spontaneous abortion. Infect Dis Obstet Gynecol.1998; 6: 8-12

16. Workowski KA, Berman SM. Sexually Transmitted Diseases treatment guidelines. US Department of Health and Human Services 2010; Centre for Disease Control and prevention.

17. Rekart ML, Gilbert M, Mezza R, Kim PH, Chang M, Money DM et al. Chlamydia public health programs and epidemiology of Pelvic inflammatory disease and ectopic pregnancy. JID. 2013;207:31-8.

18. Stamm WF. Chlamydia trachomatis infections progress and problems. J infect Dis. 1999; 179:380-3

19. Lawton B, Rose S, Bromhead C, Brown J, Mac Donald J, Shepard J. Rates of Chlamydia trachomatis testing and infection in pregnant women. The $\mathrm{N} \mathrm{Z}$ Med, J. 2004;117:(1194):1-7.

20. Andrews WW, Goldenberg RL, Mercer B, Ians J Meis P, Moawad A et al. The preterm prediction study association of second trimester genitounrinary Chlamydia infection and subsequent spontaneous preterm birth. Am J Obstet. Gynecol. 2000;183(3):662-8.

21. Koumans EH, Rosen J, Van Dyke MK et al. Prevention of mother to child transmission of infection during pregnancy: Implementing the recommended interventions. United States 20032004. Am J Obstet Gynecol. 2012;206(2):158.e1-11.

22. Golden MR. Expedited partner therapy for sexually transmitted diseases. Clin Infect Dis. 2005;41:630-3.

23. McComick MC. The contribution of low birth weight in infant mortality and childhood morbidity. N Engl J Med. 1985;312:82-90.

24. Pararas M, Skevaki C, Kafetzis D. Preterm birth due to maternal infection: causative pathogens and mode of prevention. Euro J CLin Microbiol Infect Dis. 2006;25(9):562-9.

25. Li YH, Wu QL, Zou YM et al. Relationship between the colonization of group B streptococci Mycoplasma and Chlamydia trachomatis infection and spontaneous abortion due to early embryonic death zhongguuo Yi xue Yuan Xue Bao. 2010;32:513-25.

26. Fogler AT. Maternal chlamydia trachomatis infections and preterm birth: The impact of early detection and eradication during pregnancy. Matern child Health. 2014;18:1795-802. 
27. Behman RE, Butler AS. Preterm birth causes consequences and prevention. Washington DC. National Academy Press. 2007.

28. Blas MM, Canchihuaman FA, Alva IE, Hawes SE. Pregnancy outcomes in infected with Chlamydia trachomatis a population based cohort study in Washington State Sex Transm Infect. 2000;83:314-8.

29. Silveira M F, Ghanem KG, Erbelding EJ et al. Chlamydia trachomatis infection during pregnancy and the risk of preterm birth a case control study. Int J STD AIDS. 2009;20465-9.

30. Yalti E, Erysoy GS, Tanir MH. Prevalence of Chlamydia trachomatis infection in pregnant women with preterm laour PROM and abortion. Firat Med J. 2015;20(3):142-7.

31. Simmons LE, Rubens CE, Darmstardt GL, Gravett MG. Preventing preterm birth and neonatal mortality exploring the epidemiology causes and interventions. Sem Perinat. 2010;34:408-15.

32. Wax JR, Cartin A, Pinette MG. Biophysical and Biochemical screening for the risk of preterm labour. Clin Lab Med. 2011;30:693-707.

33. Oda N, Takkeuchi K, Tanaka A, Maruo T. Obstetric risks factors associated with the development of periventricular leucomalacia in preterm infants born to mothers complicated by placenta previa. Fetal Diagn Ther. 2008;24:345-8.
34. Bhuta ZA, Lassi ZS, Blanc A, Donnay F, Linkages among reproductive health, maternal health and perinatal outcome. Sem. Perin. 2010;34:434-45.

35. Baud D, Goy G, Jaton K, Osterheld MC, Blumer S, Bore $\mathrm{N}$, et al. Role of Chlamydia trachomatis in miscarriage. Emerg Infect Dis. 2011;17(9):1630-5.

36. Baud D, Regan L, Greub G. Emmerging role of Chlamydia and Chlamydia-like organism in adverse pregnancy outcomes. Curr Opin infect Dis. 2008;21:70-6.

37. Wilson W, Lowdermilk DL. Maternal Child Nursing Elsvier Publishers UK 2006.

38. Popovich DM, McALhany M. The practitioner's care and guidelines for infants born to Chlamydia positive mothers. NBIN. 2004;4(1):51-5.

39. Sutton MY, Sternberg M, Zaidi A, Loius ME, Markowitz IE. Trends in Pelvic inflammatory Disease among hospital discharges and ambulatory visits United States 1985-2001. Sex Transm infect. 2005;32:778-84

40. Rekart ML, Brunham RC. Epidemiology of Chlamydial control; are we loosing ground? Sex Transm infect. 2008;84:87-91.

Cite this article as: Siakwa M, Kpikpitse D, Azanu W, Kuganab-Lem RB, Hanson-Owoo E. Chlamydia trachomatis infection and maternal outcomes in Southern Ghana. Int J Reprod Contracept Obstet Gynecol 2016;5:1108-13. 